Madrygal. Revista de Estudios Gallegos

ISSN: 1138-9664

\section{As capas da revista Nós}

Ana Acuña Trabazo ${ }^{1}$; Afonso Vázquez Monxardín ${ }^{2}$

Madrygal súmase á celebración do centenario da revista Nós (30 de outono de 1920) coa reprodución dunha das súas capas máis representativas. Nós, ao longo dos seus quince anos de vida, tivo varias capas que, a pesar da súa evolución estilística, compatiron sempre tres trazos: a autoría, todas saíron da pluma e imaxinación de Castelao; a vontade de identificación simbólica coa Terra (dolmens, campás, cálices, fiandeiras...); e o feito de reservaren totalmente a información para o interior, pois nada hai en ningún número semellante a un índice externo nin na capa nin na contracapa.

A imaxe da capa da revista a partir do número 10 converteuse, nos nosos tempos, nunha icona emblemática da cultura galega do século $\mathrm{XX}$, reproducida en varios soportes populares (camisolas, xerras...) e favoreceu a identificación social coa publicación periódica máis emblemática da cultura galega do século XX, esa que deu nome a un grupo de homes, ao conxunto dunha xeración e a un tempo histórico. En palabras de Bonet Correa (1983: 6), a quen traducimos, Nós constitúe un dos capítulos máis brillantes e creativos da cultura galega do noso século.

Podemos establecer tres momentos cronolóxicos segundo as mudanzas sufridas polas capas da revista que homenaxeamos. As capas, como a maioría dos deseños da revista Nós, son da autoría de Castelao, o que foi o seu director artístico (así consta na publicación dende o número 19).

1. Os primeiros nove números (1920-1922) de Nós levan unha cuberta branca e limpa. A do número 1 é tan sobria que se reduce ao título da revista (na parte superior esquerda) e á data (na parte inferior dereita). O tipo de letra do nome é parecido ao que o mesmo Castelao creara para outras publicacións inmediatamente anteriores (A Nosa Terra, suplemento Nós de El Noroeste) e que será utilizado posteriormente como único elemento decorativo das capas en varias obras literarias feitas polo rianxeiro (caso de Na noite estrelecida, de Ramón Cabanillas). Certamente, un tipo de letra

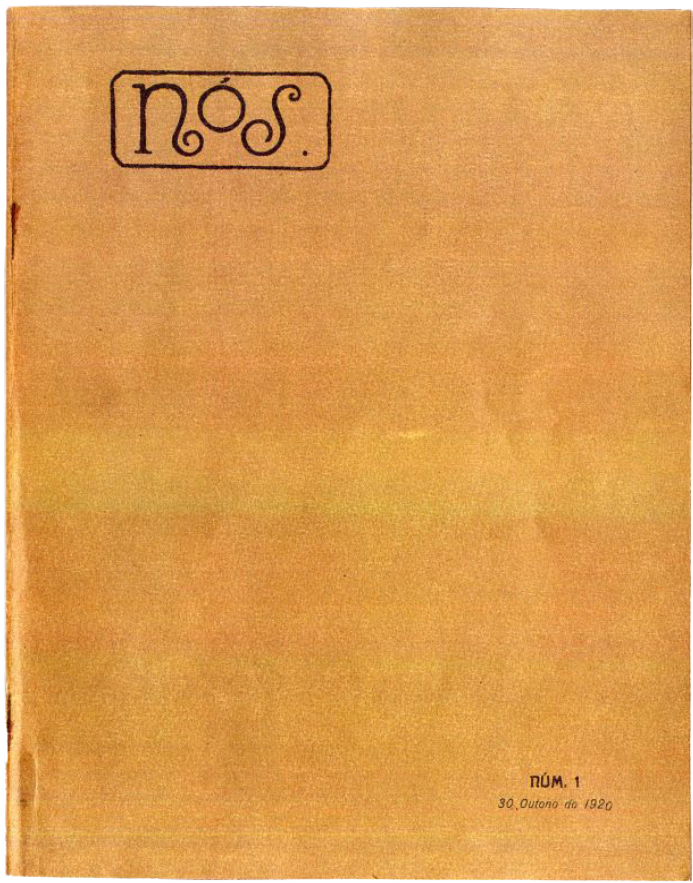

Capa do número 1 da revista Nós (1920) (fonte: Galiciana)

Universidade de Vigo. Departamento de Filoloxía Galega e Latina.

Correo-e: ganime@uvigo.es.

2 Correspondente da RAG.

Correo-e: monxardin@gmail.com. 
baseada nas inscricións medievais, que xa fora usada no século XIX (Galicia Diplomática) e que contou con varios recreadores e difusores no primeiro terzo do XX (ademais do propio Castelao, foi empregada por Carlos Sobrino e Camilo Díaz Baliño).

Dos números 2 ao 9, ademais do título, Castelao insire debuxos sinxelos que coloca na posición central da capa. Estes debuxos, de difícil explicación pola súa simboloxía, foron aparecendo como elementos decorativos noutras partes e números da revista (como colofóns, cabeceiros, letras capitais) e tamén noutras publicacións. Recordamos ese repertorio de pequenos debuxos:

- unha vella (frade ou druída) bicando unha caveira,

- unha campá tanxida,

- unha Piedade (ou a Virxe das Angustias),

- un videira ou un sanguiño (elemento simbólico druídico) enraizado nunha caveira (ou agarrándoa a través das poutas-raíces) e peteirado por un paxaro,

- unha man que empuña, como unha espada, a cruz de Santiago (elemento de identificación colectiva previo á difusión do escudo) ou ben agarra a espada máxica de Pontevedra (sobre a que teñen intercambiado comentarios V. Risco e A. Losada) ou mesmo a espada do Santo Grial,

- un dolmen e unha estrela,

- un neno que mira pola fiestra.

2. A segunda cuberta aparecerá entre os números 10 (1922) e 31 (1926), con 4 reaparicións posteriores ( $\mathrm{n}^{\circ} 114$ a 118 de 1933). Luís Seone (1970: 51), a propósito dela, di que "Os novos debuxos de Castelao da tampa son aínda, co seu barroquismo, típicamente "art nouveau" coma moitas das ilustracións que facía entón". Castelao aplica nesta capa o aprendido durante a súa primeira viaxe a Europa e crea unha capa retablo, de aparencia románica, ateigada de motivos vexetais e figuras, en varios niveis:

- Enmarcada por unha cenefa de puntos brancos que tamén rodea o nome da revista, no primeiro nivel dese retablo, na parte superior e no centro (entre o número e a data), sitúase un cáliz (ou Santo Grial) baixo unha estrela.

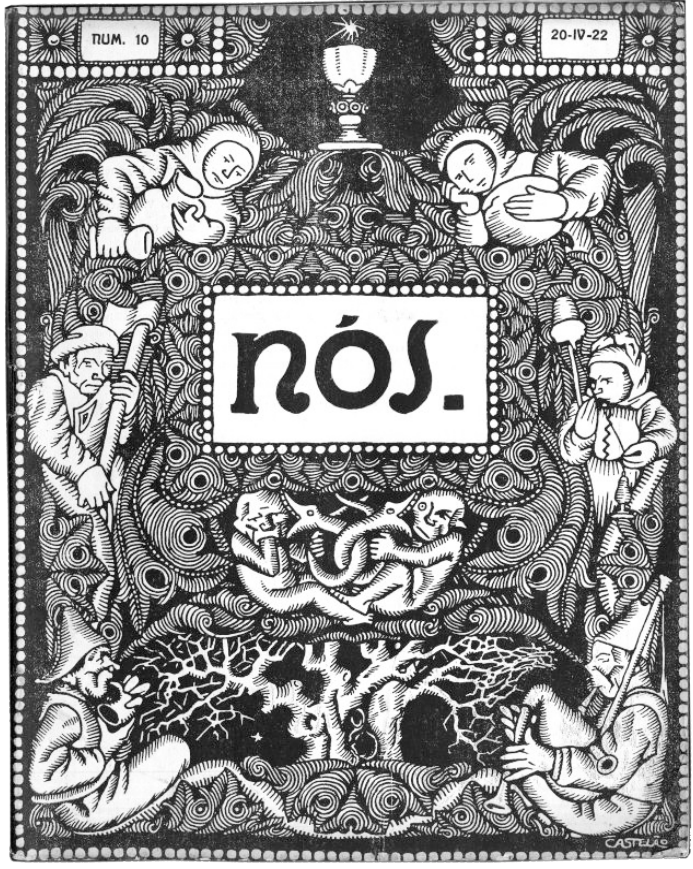

Capa do número 10 da revista Nós (1922) (fonte: Galiciana)

- Dúas figuras femininas cunha bola de pan e unha xerra de viño sitúanse no seguinte nivel, por debaixo, e cunha posible lectura relixiosa ou laica. Estas figuras inspíranse nuns capiteis vistos en París (Musée de Cluny) e foron reproducidos no seu Diario por Castelao.

- No nivel inferior dúas novas figuras (masculina e feminina) portan ferramentas propias do seu oficio (leñador e fiandeira) e poden simbolizar a forza e a tradición.

- Por debaixo, outras dúas figuras masculinas e sedentes tocan instrumentos musicais (corno e gaita).

- As seis figuras parecen dirixir a súa mirada ao nome da revista, centrado e enmarcado, ou ben a un capitel, situado por baixo, no que se integran uns monstros (devoradores ou devorados por serpes fantásticas cuxos corpos se entrecruzan). Os monstros son, en realidade, a fiel reprodución de figuras vistas nun capitel en Munich (Bayerisches Nationalmuseum) e que incluirá tamén no seu Diario o autor de Cousas.

- Debaixo deste capitel de aparencia románica, e entre os músicos, unha árbore (carballo ou castiñeiro milenario, símbolo de vida e de Galicia) nunha noite estrelecida. 


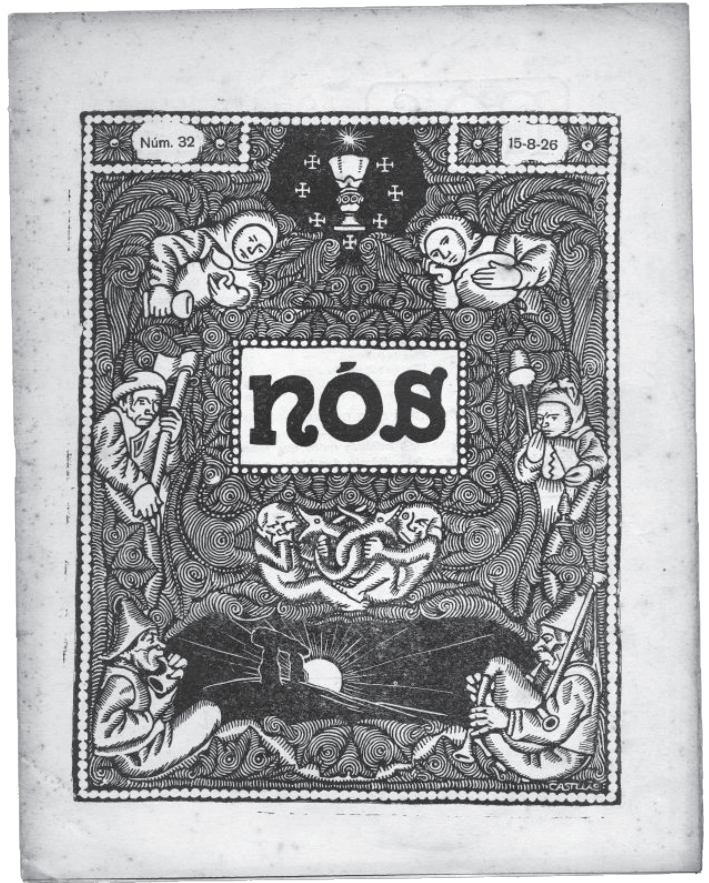

Capa do número 32 da revista Nós (1926) (fonte: Galiciana)

3. A versión definitiva da capa de Nós é a que aparece no número 32 (1926) e ata o final da revista. As mudanzas son perfectamente identificables:

- A ilustración non ocupa toda a capa e hai unha marxe en branco, o cáliz (ou Santo Grial) aparece agora rodeado por 7 cruces (símbolo, na mitoloxía galeguista, das sete cidades galegas do Antigo Reino de Galicia).

- As letras do título engrosan e perden o punto final, ademais o "s" une os seus extremos.

- Por último, a árbore que sostiña a maior parte das figuras do retablo é substituída por un amencer detrás dun dolmen.

A partir do número 10, ou sexa, desde o comezo da utilización da segunda capa, as cores darán vida, de forma nada sistemática, a moitos dos números da revista Nós. Parece que existe unha continuidade entre as cores destes números e as coleccións de libros editados nas imprentas Lar e Nós que, tamén, utilizarían como elementos decorativos das súas edicións figuras (campá, dolmen, sanguiño, neno na fiestra etc) aparecidas desde os primeiros números da revista.

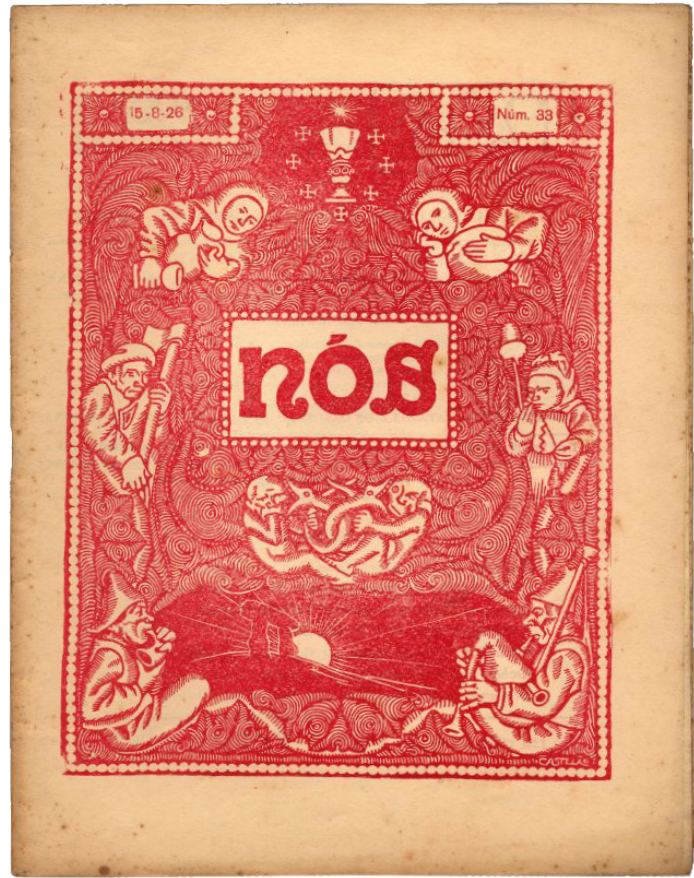

Capa do número 33 da revista Nós (1926) (fonte: Galiciana)

Como curiosidade, queremos sinalar que hai dúas reproducións ou reutilizacións de época. Por unha banda, no número de primeiro de ano de 1925, o xornal Galicia de Vigo usa esta mesma capa, reproducíndoa en espello, ou sexa as figuras que van á esquerda nun caso

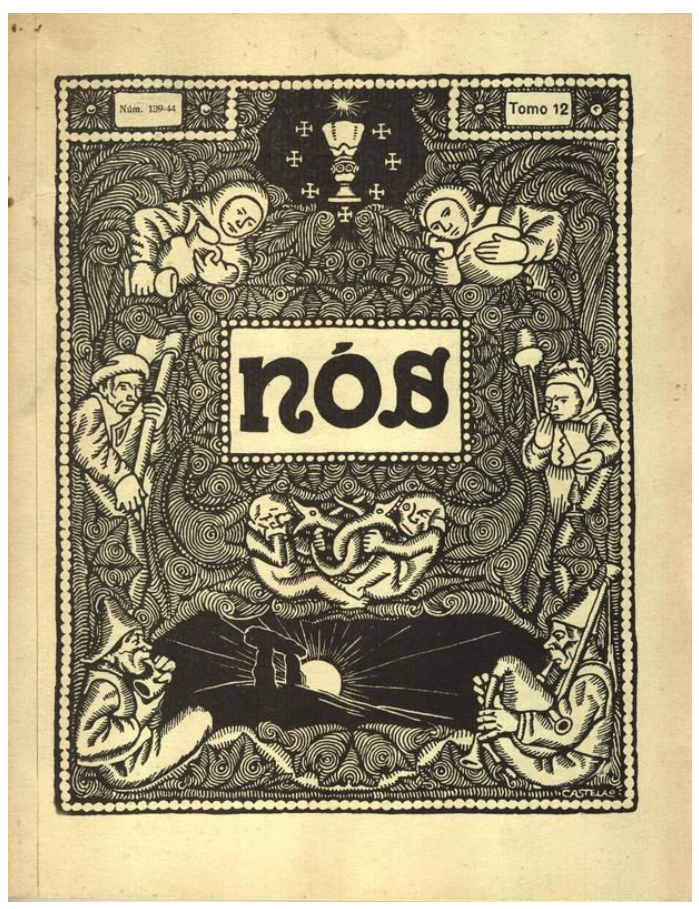

Capa do número 139-144 da revista Nós (1935) (fonte: Galiciana) 
van á dereita no outro, e con algunhas variacións que afectan, principalmente, ao capitel central dos monstros que aparece abeirado por outros dous capiteis animalísticos, e á introdución dunha vieira, símbolo xacobeo, por baixo do cáliz. Aparece asinada por Castelao, aínda que a realización dos trazos dista bastante das outras capas.

Por outra banda, en 1939, no Día de Galicia -e desde ese ano reproducido outras vecesaparece a capa definitiva de Nós como capa da revista Vida Gallega da Habana coa única modificación da cartela central para incluír o novo título en vez do clásico Nós. É posible que a

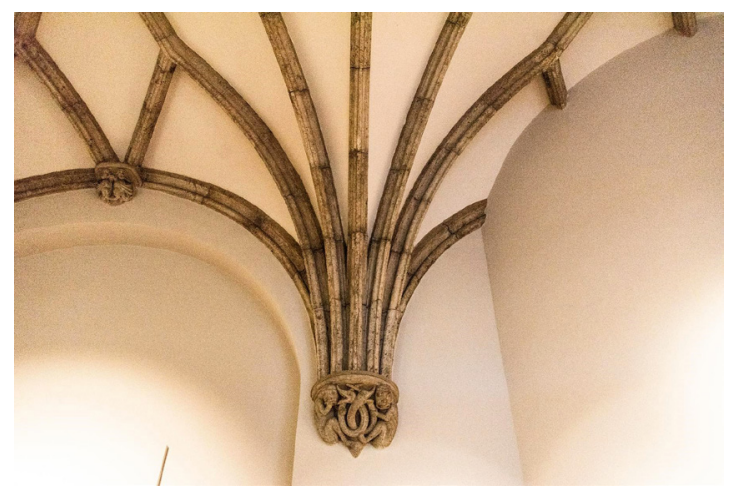

reelaboración da capa -moi delicada, desde logo- fose feita polo propio Castelao no seu paso pola illa en datas inmediatamente anteriores á publicación.

Acompañamos esta crónica coa imaxe do capitel visto por Castelao durante a súa primeira viaxe a Munich. Esta imaxe foi fornecida por Matthias Weniger para a exposición Galicia, de Nós a nós, comisariada pola autora e o autor deste traballo. Precisamente, tanto o catálogo (Vázquez-Monxardín 2020: 148) como unha das visitas relatorio (Barro 2020) dependentes da citada exposición ofrecen información de interese sobre o deseño da revista Nós e as capas.

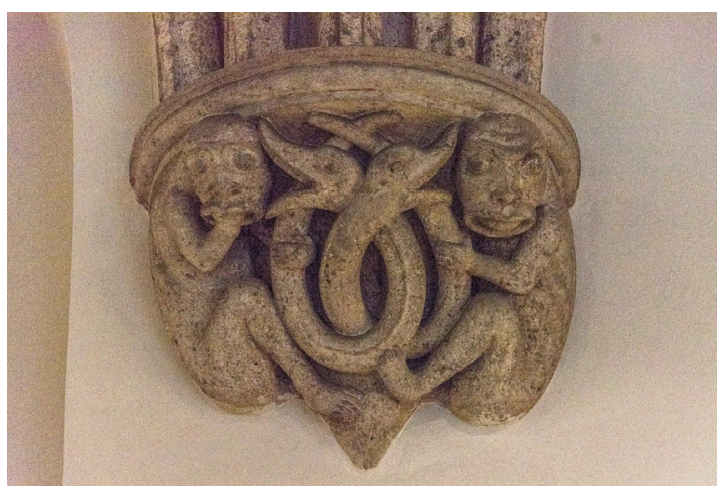

\section{Referencias bibliográficas}

Barro, Pepe (2020): “O deseño que hai en Nós”. Santiago de Compostela: Museo Centro Gaiás, https:// www.youtube.com/watch?v=YzsNe31Q0o0\&feature=youtu.be [data de consulta: 04/12/2020].

Bonet Correa, Antonio (1983): "Prólogo", en $\mathrm{M}^{\mathrm{a}}$ V. Carballo Calero, La ilustración en la revista «Nós». Ourense: Deputación, pp. 6-7.

Seoane, Luís (1970): “Algúns aspeitos de Nós”, Nós. Boletín mensual da cultura galega. Ed. facsímile, $n^{o}$ 145, 30 outubro 1970. Homenaxe da Real Academia Galega. A Cruña: Real Academia Galega, pp. $51-52$.

Vázquez-Monxardín Fernández, Afonso (2020): “As portadas de Nós”, en Galicia de Nós a nós. Catálogo da exposición. Santiago de Compostela: Xunta de Galicia, p. 148. 